\title{
VIGILÂNCIA LÍQUIDA: VARIAÇÕES SOBRE O PANOPTISMO
}

BAUMAN, Zygmunt. Vigilância líquida. Rio de Janeiro: Zahar, 2014.

Rafael Leopoldo*

O livro Vigilância líquida é um diálogo, ou melhor, uma entrevista entre dois conhecidos sociólogos, Zygmunt Bauman e David Lyon. Devido ao fato do livro ter como gênero literário a entrevista ele perpassa características da oralidade, os elementos de uma entrevista jornalística geralmente fazem de uma leitura algo mais fluido e conciso. Contudo, é claro que se trata de um texto sobre sociologia e tem a densidade deste campo de saber, mas a obra vai além do escopo sociológico se ramificando de forma interessante para outros saberes. Bauman há muito tempo já deixou de escrever somente para os sociólogos, assim as suas temáticas ganham uma maior amplitude como, também, o gênero literário do Vigilância líquida chega mais perto de uma tonalidade popular sem perder a agudez e profundidade de suas elaborações teóricas. Há uma cortesia tanto de Bauman quanto de David Lyon com relação a clareza desse livro e isso é transposto por meio da forma e por meio do conteúdo.

O tema central da obra é a vigilância, sobretudo uma vigilância entendida sobre o viés de uma modernidade líquida em contraponto a uma duradoura e sólida. A ideia de liquidez, de flexibilidade, de fluidez já é uma categoria consagrada no pensamento de Bauman que ele usa como eixo chave para as suas análises e esta categoria não deixa de perpassar o livro citado. A vigilância para Bauman, então, torna-se vigilância líquida e esta fluidez vai estar como plano de fundo teórico de todo o texto, de cada um dos capítulos. A obra de Bauman e Lyon é constituída por sete tópicos: 1) drones e mídia social; 2) a vigilância líquida como pós-pan-óptico; 3) ausência, distanciamento e automação; 4) in/segurança e vigilância; 5) consumismo, novas mídias e classificação social; 6) investigando eticamente a vigilância; 7) agência e esperança. Estes são os temas principais do texto e podemos ver que em três deles (segundo, quarto e sexto)

\footnotetext{
* Mestre em psicologia pela Universidade Federal de Juiz de Fora (UFJF). Pós-graduado pela Faculdade LatinoAmericana de Ciências Sociais (FLACSO). Graduado em filosofia pela Pontifícia Universidade Católica de Minas Gerais (PUC-MG). Reflexão produzida no Grupo de Estudos "Vigilância e (in)segurança: das sociedades disciplinares à sociedade de controle”. E-mail: ralasfer@gmail.com.
}

Sapere Aude - Belo Horizonte, v. 6 - n. 12, p. 894-902, Jul./Dez. 2015 - ISSN: 2177-6342 
o termo vigilância é citado explicitamente. Porém, essa reflexão não tende a sintetizar cada objeto do pensamento dos autores, mas sim, adentrar em um tema que sofre determinadas variações e por meio dele problematizar a (in)segurança, a vigilância, a subjetividade na atualidade mesmo que de uma maneira sucinta.

Assim sendo, esse apontamento tem como objetivo fazer uma análise crítica, mas voltando para os elementos que tocam a questão da (in)segurança, da vigilância e da subjetividade. Os tópicos foram abordados com maior acuidade no capítulo segundo intitulado "A vigilância líquida como pós-pan-óptico", dessa forma, é forçoso fazer uma análise mais apurada de tal capítulo. A variação permanente que já havíamos salientado é a questão do panóptico. O panóptico será o tom modular que vai sofrer alterações teóricas no percorrer do nosso texto, seja ela no formato de panoptismo, de pós-panoptismo, de banoptismo ou ainda de sinoptismo.

Poderíamos situar o livro de Bauman e Lyon dentro de um ambiente teórico de autores que fazem um esforço intelectual de compreensão das sociedades pós-disciplinares. Sociedades disciplinares tal como analisadas por Michel Foucault e pós-disciplinar tal como analisada por Gilles Deleuze compreendendo as sociedades como sociedades de controle. Os dois textos fundamentais para nos ambientarmos ao tema da vigilância, ao menos via uma leitura filosófica, são os dos filósofos já citados, Michel Foucault com o livro Vigiar e punir e Gilles Deleuze com o texto Post-Scriptum sobre a sociedade de controle. Todavia, por mais que estes dois textos sejam seminais eles são restritos para pensar a atualidade. Ambos os textos vislumbraram uma sociedade de controle, ambos os textos sinalizam o mostro que estaria por chegar, mas se configuram um material escasso diante do enredamento da contemporaneidade, daí que são necessários novos enlaces teóricos.

O filósofo Gilles Deleuze em seu Post-Scriptum sobre a sociedade de controle já apontava que Foucault havia percebido que as sociedades disciplinares estavam no seu fim. Creio que podemos ver essa passagem de uma sociedade para a outra no próprio texto foucaultiano com o conceito de pan-óptico ou ainda com o conceito de biopoder e biopolítica, a normatização biológica do humano. Foucault em Vigiar e punir usou a imagem da Peste e da Lepra para analisar a lógica disciplinar e a lógica do confinamento. Com a peste estamos em um registro 
médico-político, mas, também, envolve toda um poder administrativo-policial. No ambiente da peste tudo seria registrado, haveria o trabalho ininterrupto da escrita, registros, classificações, localizações no espaço etc. Foucault escreve que "contra a peste, que é mistura, a disciplina faz valer seu poder que é de análise" (FOUCAULT, 2009, p. 188). A lepra, por sua vez, estaria no registro dos encarceramentos. A lógica é a da cerca, o intuito é um exílio dos leprosos por meio do confinamento. Deixa-se o leproso juntamente com tantos outros leprosos formando uma massa sem diferenciação. Desta maneira, ela é de fato, distinta da peste entendida como referência para uma tecnologia disciplina. Importante observar que para Foucault a tecnologia disciplinar pode colonizar, por exemplo, o ambiente do confinamento, organizando-o, disciplinando e dando ordem aos corpos até então indiferenciados.

Outro elemento tratado por Foucault como uma tecnologia disciplinar é o famoso panóptico. O panóptico (“o olho que tudo vê”) é uma referência ao projeto arquitetônico de uma prisão do filósofo e jurista Jeremy Bentham. Neste projeto haveria uma torre central que poderia ver os presos em cada uma de suas celas, porém os presos não veriam quem poderia estar vigiando-os. Deste modo, geraria um sentimento de constante vigilância, de uma vigilância ininterrupta. Se quando havia os presos na masmorra o intuito era trancar, privar de luz e visibilidade, agora, com o panoptismo a ideia é trancar, dar luz e gerar visibilidade, sendo que " $a$ visibilidade é uma armadilha" (FOUCAULT, 2009, p. 190. Itálico nosso), posto que quanto maior o campo de visibilidade do prisioneiro, maior seria o saber e o poder sobre aquele corpo. Neste momento é importante observar que o panoptismo não é somente uma estrutura física, mas também, uma tecnologia de poder que induz um estado consciente de permanente visibilidade. $\mathrm{O}$ panoptismo entendido como uma tecnologia poderia colonizar outros ambientes, já que ele é ramificável e flexível. Esta compreensão já está nas próprias cartas de Bentham (carta 19, 20 e 21), ou seja, a mesma estrutura panóptica (o princípio da inspeção) poderia ser utilizado nos hospícios, hospitais e escolas (2008).

Se as disciplinas exerciam um poder sobre os corpos dóceis, corpos submissos, mas, também, corpos úteis e aperfeiçoáveis o biopoder (poder de fazer viver) muda de registro, porque ele trabalha não no nível individual, mas sim, no nível do indivíduo enquanto espécie, ou seja, a massa, a população. O primeiro diz respeito a anatomopolítica e o segundo a biopolítica. Tal biopoder para Foucault aparece no final do século 18 com toda uma gama de regulamentações,

Sapere Aude - Belo Horizonte, v. 6 - n. 12, p. 894-902, Jul./Dez. 2015 - ISSN: 2177-6342 
principalmente, no âmbito da saúde e da educação e este poder é interessante, porque poderíamos ver nele outro elemento de uma passagem para as sociedades de controle, posto que não há somente uma análise dos arquipélagos carcerários, dos ambientes de confinamento, mas há com este conceito uma expansão da análise que perpassa demais elementos, desde a educação, a saúde, a importância da seguridade social ao problema do racismo, da exclusão de determinados grupos etc. Creio com estes dados ter salientado, dois tópicos que podemos entender na própria obra do Foucault como uma passagem para esta outra sociedade que é a de controle.

O termo "sociedade de controle" foi consagrado por Deleuze no seu pequeno texto já citado. No texto do Deleuze é enfatizado que todos os ambientes fechados estão em crise: família, escola, fábrica, hospital, prisão etc., porém, não se trata somente de crises de instituições, porque ademais o capitalismo se transforma, um primeiramente baseado na produção e o outro se transforma em um capitalismo financeiro. O indivíduo também parece ser outro, o primeiro o indivíduo que aparenta ter quitado suas dívidas e o outro na sua dívida infinita. Mas, talvez, o tema principal seja que se em um momento o foco era a disciplina o outro é o controle, e ambos são diferentes. O primeiro faz referência a um lugar fechado e de criar determinada ordem; o segundo de um controle a céu aberto - pode-se criar mais espaços de livre circulação sempre, mas juntamente a estes espaços é criado todo um controle da mobilidade. Assim, exemplificamos a diferença entre disciplina dos ambientes de confinamento e o controle ao ar livre, Deleuze usa respectivamente a imagem da toupeira e da serpente como metáfora destes dois ambientes e não hesita em escrever que "os anéis de uma serpente [sociedade de controle] são ainda mais complicados que os buracos de uma toupeira [sociedade disciplinar]" (DELEUZE, 2013, p.230).

Colocados esses elementos de forma concisa a respeito da filosofia de Foucault e Deleuze, podemos voltar para o segundo capítulo da obra Vigilância líquida de Bauman intitulado “A vigilância líquida como pós-pan-óptico". Penso que esse capítulo são variações sobre o tema do panoptismo (pós-panóptico, banóptico e sinóptico) e uma tentativa de refletir sobre a sociedade pós-disciplinar. Deste modo, é importante salientar quais são as armas teóricas no diálogo de Bauman e Lyon. A primeira mutação no conceito é feita por Bauman, o sociólogo entende que vivemos em um mundo “pós”-panóptico. Com relação a este prefixo é necessário enfatizar dois pontos: 
1. Bauman parece compreender o pan-óptico não como uma tecnologia de vigilância, mas fortemente como um aparato físico de vigilância. O panoptismo para o autor estaria dentro de sua conceituação de uma "modernidade dura" em contraponto a uma "modernidade líquida". Assim, o "pós" do Bauman faz referência a outras formas de panoptismo que seriam de aplicabilidade mais baratas do que o panóptico foucaultiano que seria de difícil aplicabilidade e restrito a determinados ambientes.

2. É importante salientar que este "pós" no conceito de Bauman não significa um "fim", porque para o autor o panoptismo estaria armado de formas que Foucault nem imaginaria. Todavia, este panóptico não teria a mesma centralidade na nossa sociedade, mas sim, estariam vinculados a partes "não administrativas" da sociedade como, por exemplo, os campos de confinamento, as prisões, as clínicas psiquiátricas etc. A citação destes ambientes por Bauman somente faz confirmar o seu entendimento do panoptismo como um espaço físico e não, necessariamente, como uma tecnologia de vigilância e poder.

Bauman entende que na atualidade o panóptico não tem uma centralidade e coloca-o como um aparato de vigilância de uma minoria. Esta minoria para Bauman diz respeito a categoria já utilizada no livro Vidas desperdiçadas de "lixo humano" ou ainda de "refugo humano". Esta categoria corresponde aos excluídos e aos restos. O sociólogo chega a relacionar estas minorias com a compreensão de um homo sacer como analisado por Giorgio Agamben. O conceito de Agamben diz respeito a uma vida desprovida de valor, seja na perspectiva humana ou na perspectiva divina. Um indivíduo que não se define por leis positivas e nem por ser um portador dos direitos humanos que precederia as normas jurídicas. Para Bauman o homo sacer seria a principal categoria do "refugo humano", aquele que não é e nunca será útil para a sociedade. O panoptismo teria o poder de vigilância destes sujeitos, mas o pós-pan-óptico parece estar noutro âmbito. Penso poderíamos envolver este pós-pan-óptico numa forma de "subjetivação", mesmo que o autor não use esta palavra com frequência. A imagem para este processo de subjetivação é o homem-caramujo com o seu panoptismo-pessoal em suas costas.

Bauman quando argumenta sobre este homem-caramujo, sobre esse novo panoptismopessoal cita o livro Discurso da servidão voluntária de Étienne de la Boétie. A servidão voluntária apareceria de forma exemplar no ambiente empresarial onde há a luta para se obter o sucesso a partir de uma ferrenha disciplina, obediência, conformidade, respeito à ordem etc., é 
válido lembrar que a noção de disciplina de Foucault mostra que se o corpo ganha em utilidade ele perde em poder político, já que ele está sempre submisso. Bauman vê a disciplina na tentativa de uma gama de indivíduos de serem vencedores no ambiente de trabalho, Deleuze por sua vez já salientava que "muitos jovens pedem estranhamente para serem 'motivados', e solicitam novos estágios e formação permanente; cabe a eles descobrirem a que estão sendo levados a servir, assim como seus antecessores descobriram, não sem dor, a finalidade das disciplinas" (DELEUZE, 2013, p. 230). O indivíduo introjetaria estas linhas duras (para utilizarmos outro termo deleuziano) de uma sociedade de controle, na empresa os líderes, os gerentes passariam para os demais a lógica da vigilância, do panoptismo-pessoal, do do it yourself ("faça você mesmo"), assim as relações de poder seriam verticais e horizontais e:

o propósito é aproveitar o total da personalidade subalterna e todo seu tempo de vigília para as finalidades da empresa. Trata-se de um expediente considerado, e não sem motivo, infinitamente mais conveniente e lucrativo que as medidas pan-ópticas, sabidamente caras, incontroláveis, restritivas e trabalhosas. A servidão, com a vigilância do desempenho 24 horas por dia, sete dias por semana, está se tornando plena e verdadeiramente, para os subordinados, uma tarefa do tipo "faça você mesmo". (BAUMAN, 2015, p.61).

Aproveitar a personalidade subalterna, preferencialmente 24 horas por dia 7 dias por semana juntamente com uma vigilância que poderíamos chamar de 24/7, a conclusão lógica é o fim do sono no capitalismo tardio como apontado por Jonathan Crary (2014). Diante deste processo de trabalho e vigilância o indivíduo não precisaria do antigo panóptico (que para Bauman seria caro e dispendioso), pois ele já teria em si mesmo o seu panoptismo-pessoal (autovigilância e a vigilância do outro), e isso é o que havíamos chamado de um processo de subjetivação, uma subjetivação policial de uma continua autovigilância, mas também, com as características do sujeito empreendedor de si, do empresário de si mesmo. Esta é, basicamente, a leitura que Bauman faz de um panoptismo nas sociedades pós-disciplinares. Todavia, ainda há outras variações a respeito do panóptico, trata-se do ban-óptico.

A segunda variação sobre o tema do panóptico é o "ban-óptico". O banóptico, por sua vez, não é um conceito cunhado por Bauman, mas sim, por Didier Bigo. Penso que esta seja a variação mais importante, ao menos, para pensarmos os estudos de vigilância e (in)segurança na América Latina. O banóptico seria um dispositivo ( "dispositif" no sentido de Foucault) com três 
critérios: 1) excepcionalismo; 2) criação de perfil e contenção de estrangeiros, do lixo humano se pensarmos juntamente e com as categorias do Bauman; 3) um imperativo normativo com relação a mobilidade. Daí que Bigo chega a falar de um soft fascismo no seu texto Globalized (in)security: the field and the ban-opticon. A análise de Bigo seria aplicável as minorias, aos marginais, porque diz quem é bem-vindo e quem é malquisto, criando categorias de pessoas, destas categorias se relaciona a mobilidade, quem deve passar e quem deve ficar em determinado espaço. Um exemplo claro é pensar em determinados indivíduos que são categorizados, por exemplo, como perigosos e assim tem sua mobilidade reduzida, pois ele estaria entre aquele que não podem atravessar determinadas fronteiras. O mesmo se daria com os párias da sociedade, um exemplo bem brasileiro é pensar o Rio de Janeiro e como os moradores de favelas são, geralmente, impedidos de frequentar determinados ambientes (mesmo o ambiente público como a praia). Traça-se um perfil, coloca-se imperativos normativos e limita a mobilidade. Uma diferença deste banóptico com relação ao foucaultiano é a sua conexão mais essencial com a insegurança e não com a disciplina. Isso se dá, principalmente, devido aos atentados de 11 de setembro de 2001 aos Estados Unidos e a criação midiática de uma paranoia, de um medo constante. Na América Latina poderíamos relacionar o banoptismo também com a insegurança, mas as nossas inseguranças são outras que não faz referência direta a um terrorismo internacional. Bauman corrobora com Bigo e diz que em determinado momento usa-se o banóptico para excluir o lixo humano e depois o panóptico para vigiá-los, os dois podem facilmente se embrenharem em um processo de exclusão continua, assim é possível parafrasear Foucault: banir e vigiar.

A terceira e última variação sobre o panoptismo é o "sinóptico". O sinóptico, por sua vez, é um neologismo do sociólogo Thomas Mathiesen que contrasta o panóptico com a mídia de massa. O panóptico seria a tecnologia de vigilância que poucos observam muitos enquanto o sinóptico seria uma tecnologia no qual muitos observam poucos. Penso que o panoptismo é cinza como os ambientes fechados e o sinoptismo é multicolor como o espetáculo: panis et circenses. Para Bauman o sinóptico do tipo de Mathiesien é um pan-óptico significante modificado, a vigilância sem vigilantes, dizendo o mesmo com outras palavras: o sinóptico é o pós-pan-óptico do próprio Bauman. Assim, Bauman pode afirmar que: 
Se o sinóptico substitui o pan-óptico, não há necessidade de construir grandes muralhas e erigir torres de vigilância para manter os internos do lado de dentro, ao mesmo tempo contratando um número incalculável de supervisores para garantir que eles sigam a rotina prescrita; com o custo adicional de aplacar o ódio latente e a falta de disposição para cooperar que a rotina monótona em geral alimenta; assim como de precisar fazer um esforço contínuo para matar no nascedouro a ameaça de uma rebelião contra a indignidade da servidão. Agora, espera-se que os objetos de preocupação disciplinares dos gerentes se autodisciplinem e arquem com os custos materiais e psíquicos da produção da disciplina. Espera-se que eles mesmos ergam as muralhas e permaneçam lá dentro por vontade própria. A recompensa (ou a promessa) substitui a punição, e tentação e sedução assumindo as funções antes desempenhadas pela regulação normativa; o sustento e o aguçamento dos desejos tomam o lugar do policiamento, caro e gerador de discórdias; portanto, as torres de vigilância (tal como toda a estratégia destinada a estimular a conduta desejável e eliminar a indesejável) foram privatizadas, enquanto o procedimento de emitir permissões para a construção de muralhas foi desregulamentado. Em vez de a necessidade caçar suas vítimas, agora é tarefa dos voluntários caçar as oportunidades de servidão (o conceito de "servidão voluntária" cunhado por Étienne de la Boétie teve de esperar quatro séculos até se transformar no objetivo comum da prática gerencial) (BAUMAN, 2014, p. 72-73).

Há nesse momento novamente a ideia de Bauman de um pós-pan-óptico e do indivíduo entendido como um homem-caramujo que leva consigo o seu panoptismo-pessoal. Este elemento já citado diz respeito ao que chamávamos de um processo de subjetivação por meio da ininterrupta vigilância e dos campos de visibilidade que são campos de saber-poder que relacionamos também com uma concepção atual de pensar o indivíduo neoliberal como capital humano, como o já citado empreendedor de si, empresário de si. Assim, penso que perpassamos as variações sobre o panoptismo na salutar troca de e-mails do Bauman e do Lyon, neste diálogo frutífero para a compreensão de uma diversidade de elementos que envolvem a segurança, a vigilância, mas também, uma forma nova de subjetivação, um indivíduo novo entremeado a esta sociedade de controle e seus escombros disciplinares.

\section{Referências:}

BAUMAN, Zygmunt. Vidas desperdiçadas. Rio de Janeiro: Zahar, 2004.

BAUMAN, Zygmunt. Vigilância líquida. Rio de Janeiro: Zahar, 2014.

BENTHAM, Jeremy. O panóptico. Belo Horizonte: autêntica, 2008.

BIGO, Didier; TSOUKALA, Anastassia. Terror, insecurity and liberty. New York/Canada, 2008.

CASTELO BRANCO, Guilherme. Michel Foucault: filosofia e biopolítica. BH: autêntica, 2015. 
CRARY, Jonathan. 24/7: capitalismo tardio e os fins do sono. São Paulo: cosac naify, 2014.

DELEUZE, Gilles. Conversações. São Paulo: ed. 34, 1992.

FOUCAULT, Michel. Em defesa da sociedade. São Paulo: martins fontes, 2010.

FOUCAULT, Michel. Vigiar e punir: história da violência nas prisões. R. J.: Vozes, 2009.

LA BOÉTIE, E. de. Discurso da servidão voluntária. São Paulo: Escuta, 1987. 